\title{
PROTEGGIÓN DE LAS MARCAS NOTORIAS Y RENOMBRADAS O FAMOSAS EN LA COMUNIDAD ANDINA DE NACIONES (CAN)*
}

\author{
WELL-KNOWN AND FAMOUS BRANDS PROTECTION IN ANDEAN \\ COMMUNITY OF NATIONS (ACN)
}

\section{José Manuel MagaÑa RufinO**}

RESUMEN: Las marcas, además de diferenciar productos o servicios de los competidores, logran atesorar un prestigio. Así nacen las figuras de las marcas notorias y renombradas o famosas, que jurídicamente demandan protección mayor a la tutelada para las marcas usuales. Sin embargo, en el ámbito internacional existe una gran confusión en cuanto a su terminología y alcance en su protección. El presente estudio pretende aportar elementos para aclarar los conceptos de estas figuras tomando como base la legislación aplicable a la Comunidad Andina de Naciones (CAN), además de hacer un análisis de su protección, así como posibles sugerencias para mejorar su tutela jurídica.

Palabras clave: propiedad industrial, marcas notorias, marcas renombradas, marcas famosas, legislación CAN, Decisión 486 GAN.
ABSTRACT: Apart from making the difference between competitor's products and services, trademarks provide prestige. In this way, the legal institutions of Well-Known and Famous Brands emerge. These brands require a higher legal protection than the required for common brands. However, there is great confusion at the international level with respect to the wording and legal protection of these kind of brands. This paper is intended to provide elements to clarify concepts related to this legal institutions, based on the applicable provisions within the Andean Community of Nations (ACN), as well as to analyze the legal protection hereof, and possible recommendations addressed to improve such legal protection.

Keywords: Industrial Property; Well Known brands; Famous Brands, ACN Law; 486 ACN Lawe.

* Artículo recibido el 19 de abril de 2017 y aprobado para su publicación el 6 de abril de 2020.

** ORCID: 0000-0001-5871-028. Doctor en derecho por la Universidad Complutense de Madrid. Profesor investigador y director de la Maestría en Propiedad Industrial, Derechos de Autor y Nuevas Tecnologías de la Universidad Panamericana (México). Miembro del Sistema Nacional de Investigadores (México), nivel 1. Lugar de residencia Aguascalientes México. Universidad Panamericana Campus Aguascalientes. Correo electrónico: mmagana@up.edu.mx.

Boletín Mexicano de Derecho Comparado, nueva serie, año LII, núm. 157, enero-abril de 2020, pp. 193-220. 
Sumario: I. Introducción. II. Principios y reglas que rigen la estructura del sistema marcario. III. La valoración de los principios y reglas en el sistema marcario. IV. Concepto y protección jurídica de la marca notoria. V. Concepto y protección jurídica de la marca renombrada. VI. Fundamentos para la protección legal de las marcas notorias y renombradas. VII. Concepto de marca notoria en la Comunidad Andina de Naciones y ausencia de la figura de la marca renombrada o famosa. VIII. Protección contra el registro de marcas notorias o renombradas en la Comunidad Andina de Naciones. IX. Protección contra el uso de una marca notoria o renombrada en la Comunidad Andina de Naciones. X. Propuesta de reformas a la D $486 C A \mathcal{N}$. XI. Bibliografia.

\section{INTRODUCGIÓN}

Las marcas son signos que además de distinguir productos o servicios de los relativos a su competencia, atesoran un prestigio o calidad. Adicionalmente, existen marcas que bien sea por su antigüedad en el mercado, o por campañas masivas de promoción, son reconocidas por el sector al cual dirigen primordialmente su oferta, y posteriormente por la generalidad del público. A efecto de proteger el prestigio ganado por el legítimo creador de este tipo de marcas, y evitar la confusión del público consumidor, tanto las marcas notorias como las renombradas o famosas deben tener una tutela legal adicional a la marca común.

No obstante, la protección legal para una marca notoria no debe ser igual que la concedida a una marca famosa. En efecto, sería injusto conceder igual tutela jurídica a una marca que sólo es conocida en el sector al cual dirige principalmente su oferta, y que, por ende, no es conocida en otros sectores, que a un signo que es reconocido por la generalidad del público.

Debido a que el término "marca notoria" o "notoriamente conocida" deviene del Convenio de París, y este ordenamiento no hace referencia a la marca renombrada o famosa, existe una gran confusión en el ámbito internacional sobre estos dos tipos de marcas. Así, hay legislaciones que distinguen entre la marca notoria y la marca renombrada o famosa (Unión Europea y México entre otras), y otras que sólo reconocen a la marca notoria (Colombia, Perú, Ecuador y Bolivia, por ejemplo) otorgando en muchos casos una protección exorbitante a marcas que sólo son conoci- 
das por el sector al cual dirigen principalmente su oferta, pero que no son conocidas por la generalidad del público.

El presente estudio pretende justificar la protección que se debe dar tanto a la marca notoria como a la marca renombrada, diferenciando su tutela, en virtud de que el conocimiento por parte del público consumidor es desigual.

También se analiza el caso de la Comunidad Andina de Naciones (CAN), que sólo reconoce a la marca notoria, analizando la problemática específica en la tutela jurídica tanto para el registro de marca como del uso de la misma por parte de un tercero ajeno a la notoriedad o fama del signo.

Por último, se presenta una propuesta para la legislación de la CAN, tanto si en el futuro reconoce a la marca renombrada o famosa como si se queda en la protección exclusiva de la marca notoria. En efecto, dado que la diferencia esencial entre este tipo de marcas es el conocimiento en el público consumidor (la marca notoria sólo es conocida en su sector, mientras que la famosa o renombrada es conocida por la generalidad del público), considero que se deben establecer mecanismos para que los titulares de este tipo de signos puedan presentar pruebas del conocimiento de la marca, bien sea en su sector o bien en la generalidad del público, y una vez acreditado ante la autoridad marcaria lo anterior, gozar de una protección automática y temporal (se sugiere una declaratoria con una vigencia limitada y sujeta a renovación si se comprueba que persiste el conocimiento del signo en el sector o en la generalidad del público) que proteja en contra del uso o registro de la marca por parte de un tercero en productos o servicios iguales o similares en el caso de la marca que ha acreditado el conocimiento en su sector, y en toda clase de productos o servicios para la marca que ha acreditado el conocimiento generalizado del público consumidor. De este modo, se evitarían litigios innecesarios, donde se tendría que acreditar en cada caso conceptos de dilución, perjuicio, menoscabo, lesión, daño injusto, etcétera, que se pueden evitar con la tutela automática, pues este tipo de elementos - como se pretende acreditar en este trabajo - se configuran claramente una vez acreditado el conocimiento del público consumidor, bien sea en el sector o en la generalidad del público en el mercado. 


\section{PRINCIPIOS Y REgLAS QUE RIGEN LA ESTRUCTURA DEL SISTEMA MARCARIO}

En términos generales, los sistemas jurídicos de protección a las marcas se sustentan en dos principios fundamentales: 1) territorialidad, y 2) especialidad (Magaña Rufino 2014, 58 y ss.), así como en dos reglas básicas: a) prioridad en el uso, y b) inscripción registral (Fernández-Nóvoa 2004).

\section{Principio de territorialidad}

El derecho de exclusividad en el uso de una marca registrada es un acto de concesión de un Estado; por tanto, tal prerrogativa no se extiende — como regla general — ${ }^{1}$ más allá de sus fronteras (Gondra 1996). Así, las marcas sólo tienen protección en el país en el cual son inscritas, ${ }^{2}$ y a efecto de acceder a una protección mundial, la marca debe ser registrada en cada uno de los países en los cuales se desea tener exclusividad sobre el signo distintivo. ${ }^{3}$ En este sentido, la marca que no es famosa o notoria en un Estado, y que no es registrada en el mismo, salvo excepciones es-

1 La excepción general a este principio lo constituyen las marcas notorias y renombradas o famosas.

2 Un precedente de aplicación de la ley más allá de un ámbito territorial lo constituye el caso Steele vs. Bulova Watch Co., en donde la Suprema Corte de Justicia de Estados Unidos aplicó la Lanham Act (ley federal que regula las marcas en EU) a actos ocurridos en México (la nulidad de la marca Bulova), y determinó condenar al pago de daños y perjuicios a un ciudadano estadounidense residente en Texas que había solicitado indebidamente el registro de la marca Bulova en México para proteger relojes. A este respecto véase Garza (2010).

3 Para este efecto, existen tratados internacionales como el Protocolo concerniente al Arreglo de Madrid relativo al registro internacional de marcas (Protocolo de Madrid). Véase Internet: http://www.wipo.int/treaties/es/registration/madrid_protocol/(consultado el 20 de enero de 2018), o registros que protegen toda una zona o comunidad, como la Marca Comunitaria de la Unión Europea regulada en el Reglamento (CE) 207/2009 del Consejo, del 26 de febrero de 2009 sobre la marca comunitaria (Reglamento de Marca Comunitaria). Véase Internet http://wrww.wipo.int/wipolex/es/details.jsp?id=5207 (consultado el 20 de enero de 2018). También el registro de una marca en un país puede hacerse a través de la figura de la prioridad consagrada en el Convenio de París para la Protección de la Propiedad Industrial (CUP). Véase Internet: http://wrwwewipo.int/treaties/es/text. $j s p$ ?file_id=288515 (consultado el 20 de enero de 2018). Sobre el derecho de prioridad, véase Fernández-Nóvoa (2004) y Jalife (2014).

Esta obra está bajo una Licencia Creative Commons

Atribución-NoComercial-SinDerivar 4.0 Internacional, IIJ-UNAM.

Boletín Mexicano de Derecho Comparado, núm. 157, enero-abril de 2020, pp. 193-220. 
peciales contempladas en la legislación local de cada país, ${ }^{4}$ o bien en los tratados internacionales (el CUP exime a las marcas notorias del principio de territorialidad), queda libre para que, en ese Estado, cualquier tercero la pueda usar e incluso registrar ante la autoridad marcaria respectiva.

\section{Principio de especialidad}

Este principio deriva de una de las finalidades esenciales de la marca: la distinción en el mercado de productos o servicios de un operador económico frente a sus competidores (Monteagudo 1995). En efecto, el titular de una marca - como regla general -5 no puede gozar de un derecho absoluto sobre el signo, pues tal derecho se encuentra ceñido al campo funcional específico al cual la marca dirige su oferta. Este principio permite que terceros empleen y - en su caso - registren la marca para aplicarla en productos o servicios diferentes a los cuales dirige su oferta el titular originario del signo (Botana 2002).

\section{Regla de prioridad en el uso}

Acorde a este principio el derecho sobre una marca se adquiere a través de la utilización efectiva del correspondiente signo en el mercado; así, tendrá derecho sobre sobre el signo, quien lo usa por primera vez, no quien lo registra (Fernández-Nóvoa 2004). ${ }^{6}$

4 En México, por ejemplo, la Ley de la Propiedad Industrial (artículo 151, fracción II, LPI) concede un plazo de tres años contados a partir de la publicación en la gaceta de la propiedad industrial de una marca registrada, para que cualquier tercero interesado pueda anular tal registro, acreditando tener un mejor derecho de uso sobre el mismo (uso anterior de la marca en México o en el extranjero). En la Decisión 486 (Régimen Común sobre Propiedad Industrial) de la Comunidad Andina de Naciones (CAN), disponible en: http:// wwre. wipo.int/edocs/lexdocs/laws/es/can/can012es.pdf (consultado el 20 de enero de 2018), no existe una disposición semejante.

5 La excepción lo constituyen las marcas renombradas o famosas.

6 El propio autor opina que la prioridad en el uso de una marca ha evolucionado para enlazarlo con la notoriedad que el propio signo ha alcanzado a través de su uso. 


\section{Regla de inscripción registral}

El nacimiento relativo al derecho sobre una marca se obtiene al inscribir el signo en el registro correspondiente, con independencia de que la marca se hubiera o no usado con anterioridad a la presentación del signo a registro (Fernández-Nóvoa 2004).

\section{LA VALORAGIÓN DE LOS PRINCIPIOS Y REGLAS EN EL SISTEMA MARCARIO}

A efecto de constituir un derecho de exclusividad sobre una marca, es innegable que se debe hacer una ponderación entre los principios y reglas que rigen el sistema marcario. En efecto, si bien los principios de territorialidad y especialidad, así como la regla de inscripción registral conceden seguridad jurídica, es claro que antes de conceder un derecho sobre un signo marcario en definitiva, debe ser tomada en cuenta la regla de la prioridad en el uso, especialmente si ese uso ha desembocado en una notoriedad o renombre por parte de un tercero.

Acorde a lo anterior, los sistemas de protección de signos marcarios de cada Estado deben establecer en sus legislaciones locales, medidas tendentes a conceder a los titulares de marcas notorias y renombradas, medios de defensa en contra de la inscripción de la marca por parte de un tercero que pretende aprovecharse de la notoriedad o renombre que el legítimo creador del signo ha logrado en ese Estado gracias a diversos factores. ${ }^{7}$

\section{CONGEPTO Y PROTECGIÓN JURÍDICA DE LA MARGA NOTORIA}

La notoriedad de una marca en el tráfico económico supone necesariamente el efectivo conocimiento de la misma en el sector destinatario del producto o servicio (público consumidor, competidores y canales de distribución). ${ }^{8}$

7 Sobre los factores que inciden en la notoriedad y renombre de una marca véase Fernández-Nóvoa (2004); González (2005) y Magaña (2010).

8 La notoriedad de la marca no siempre se observa de la misma manera en los distintos sectores del comercio; un ejemplo de esto se constata en la industria del Internet, pues, como señala Wang (2012), la industria del Internet se desarrolla rápidamente en comparación con la industria tradicional, donde la fama de las marcas se acumula por largos periodos de tiempo.

Esta obra está bajo una Licencia Creative Commons

Atribución-NoComercial-SinDerivar 4.0 Internacional, IIJ-UNAM.

Boletín Mexicano de Derecho Comparado, núm. 157, enero-abril de 2020, pp. 193-220. 
De este modo, la característica fundamental para determinar la notoriedad de una marca está constituida por el amplio conocimiento del público del sector de mercado al que pertenecen los productos o servicios distinguidos por ella. No puede haber notoriedad si no hay conocimiento. Lo que no es conocido no puede, por definición, ser notorio. ${ }^{9}$

Así, no es marca notoria sino aquella que posee conocimiento en el mercado, dentro del sector al cual dirige primordialmente su oferta, independientemente de su calidad, uso o registro. ${ }^{10}$

Por tanto, podemos definir a la marca notoria como el signo distintivo que es ampliamente conocido en el sector al cual dirige primordialmente su oferta, con independencia de su calidad, ${ }^{11}$ uso o registro en el lugar donde se demanda su protección.

Por otro lado, la marca registrada otorga a su titular el derecho exclusivo a utilizarla en el tráfico económico, identificar productos o servicios iguales o similares a aquellos para los que la marca ha sido registrada (principio de especialidad). ${ }^{12}$

Así, la protección que debe concederse a la marca considerada notoria en un Estado es la misma que la otorgada a las marcas usuales registradas (protección en productos o servicios iguales o similares), pero sin la

9 No obstante, González (2005) indica que no está de acuerdo con los autores que señalan que la notoriedad de una marca puede ser mejor reconocida cuando existe un amplio abanico de productos o servicios protegidos con la marca, que cuando van dirigidas a productos específicos, pues esta situación es propia de la marca famosa o renombrada, y no de la notoria, pues esta última debe dirigir su conocimiento a un público específico y no general.

10 Como bien señala Pacón (1993), para atribuir a una marca el carácter de notoria basta que ésta goce de difusión en el círculo de consumidores de productos o servicios idénticos o semejantes.

11 Pensemos en marcas de baja calidad, pero que por su bajo costo cumplen con la función para las que las adquiere el público consumidor (ejemplo, cámaras desechables para fotografías en la playa, paraguas o impermeables que se compran para evitar mojarse al salir de un evento, etcétera). Las marcas que identifican estos productos pueden llegar a ser conocidas perfectamente por el sector al cual dirigen su oferta, y aunque son de baja calidad permanecen en el mercado por el costo-beneficio que proporcionan a sus consumidores. Sin embargo, González (2005) indica que la calidad de un producto o servicio es un componente normalmente intenso en una marca notoria.

12 Acorde a este principio, una marca sólo tiene protección en los productos o servicios iguales o similares en los cuales se registró y pueden existir dos marcas con la misma denominación en productos o servicios diferentes. 
obligatoriedad de presentarlas a registro o acreditar su uso en tal Estado para que opere su tutela.

Por tanto, se deben resguardar y proteger las marcas notorias, a efectos de que incluso sin ser registradas o usadas en un territorio, puedan - por el grado de conocimiento entre el público al cual se dirigen- ser protegidas. ${ }^{13}$ Esta protección, como hemos señalado, se considera una excepción al principio de territorialidad de las marcas.

En resumen, a efectos de proteger tanto a los empresarios titulares de la marca notoria como a los consumidores, la tutela jurídica de la marca notoria debe enfocarse en la protección de marcas no usadas y/o registradas en su territorio, pero consideradas notorias en ese país por el sector ${ }^{14}$ al cual dirigen su oferta. La protección dispensada a la marca notoria debe romper necesariamente con el principio de la territorialidad, no así con el de especialidad.

\section{CONCEPTO Y PROTEGGión JURÍDICA DE LA MARGA RENOMBRADA}

Tradicionalmente la marca renombrada o famosa adquiría gran conocimiento entre el público consumidor merced a la gran calidad de los productos o servicios que distinguía, así como a la permanencia del signo en el mercado a lo largo del tiempo (Sanz de Acedo 2000).

En la actualidad, hay que agregar a los elementos antes señalados la gran difusión de la marca a través de campañas publicitarias, que se realizan con objeto de lograr una rápida y masiva implantación del signo en el público consumidor. ${ }^{15}$

13 Así lo dispone el Convenio de París (artículo 6 bis) y lo acepta la mayoría de la doctrina, entre ellos Kors (1999).

14 A este respecto, Casado Cerviño (2000, 103) señala que el "sector pertinente" del público comprende - no necesariamente de forma limitativa - los consumidores o usuarios reales y potenciales del tipo de productos o servicios distinguidos con la marca, los partícipes en sus canales de distribución, y los círculos comerciales que se ocupen de tales productos o servicios. Coincide también con esta opinión Marco Arcalá (1999), quien afirma que los sectores interesados o pertinentes son aquella parte del público que consume o recibe de alguna forma, productos o servicios del mismo tipo.

15 A este respecto, Monteagudo (1995), señala que el éxito de un producto en el mercado depende, cada vez en mayor medida, de la creación de una imagen atractiva asociada a la marca, que caracteriza y personaliza al correspondiente producto o servicio respecto a productos o servicios análogos de los competidores. La creación de esta imagen no es de

Esta obra está bajo una Licencia Creative Commons

Atribución-NoComercial-SinDerivar 4.0 Internacional, IIJ-UNAM.

Boletín Mexicano de Derecho Comparado, núm. 157, enero-abril de 2020, pp. 193-220. 
Por tanto, el elemento indispensable para considerar a una marca como renombrada o famosa no es su calidad, ${ }^{16}$ uso o registro, sino el conocimiento generalizado del público en el producto o servicio. ${ }^{17}$

Así, mientras la marca notoria sólo es conocida por el sector al cual dirige primordialmente su oferta, la marca renombrada o famosa es conocida por sectores a los que no dirige su oferta directamente. ${ }^{18}$

Se puede decir que la marca renombrada o famosa abarca la generalidad de los sectores que forman parte de una actividad económica, constituyendo así una suma de múltiples notoriedades expandidas por todo el tráfico mercantil (Haro 2019).

Con base en estos razonamientos podemos definir a la marca renombrada o famosa como el signo distintivo que es conocido por la generalidad del público de un Estado, independientemente de su calidad, uso o registro en el lugar donde se demanda su protección.

Por esta razón, la tutela de la marca renombrada debe romper como regla general con los principios de territorialidad y especialidad en los países donde sea conocida por la generalidad del público. ${ }^{19}$

modo alguno casual, sino que responde a estrategias de marketing y a cuantiosos desembolsos. En el mismo sentido, Lefebvre (2005), señala que la conversión de una marca ordinaria a notoria o renombrada acontece con motivo del éxito del producto o de una amplia campaña de publicidad que realice el titular de la misma.

16 Para algunos autores (Ruiz 2009), la marca renombrada o famosa debe poseer necesariamente un prestigio entre los consumidores, que constituye un bien jurídicamente independiente de la marca que debe ser protegido. De la misma opinión es Pacón (1993), quien señala que una marca renombrada debe despertar en el público consumidor una asociación con una alta calidad, una larga tradición en el mercado y una empresa destacada.

17 No obstante, hay antecedentes que indican que la fama debe ser considerada en el producto o servicio al que se aplica la marca y no procede automáticamente, aun cuando la persona sea famosa. En este sentido, la Corte de Apelaciones de EU (véase Koplow y Nelson 2019) resolvió que la fama de la cantante "Lady Gaga" no era suficiente para impedir el registro de la marca "Gaga Jeans" a nombre de un tercero, pues consideró que si bien "Lady Gaga" es una persona famosa, la marca "Lady Gaga" para ropa no lo es; alega que para que una marca se considere famosa, la denominación de la misma debe tener un reconocimiento que lo vincule con los productos que ampara.

18 Así lo mantienen entre otros Bercovitz (2006), Botana (2002), Otero Lastres (1997), González (2005) y Vargas (2019) en el sentido de que una marca renombrada o famosa generalmente tiene más valor que una marca notoria.

19 El renombre o fama de una marca puede llegar a tal extremo que el público consumidor lo asocie con el propio producto o servicio, fenómeno conocido como "vulgari- 
Cabe señalar que actualmente en la mayoría de las legislaciones nacionales e internacionales se exige acreditar diversos factores para otorgar tutela a las marcas renombradas; por ejemplo, que el afectado pruebe un riesgo de confusión y/o, conexión y/o, asociación con la marca del tercero que le afecta, o bien demostrar que el tercero causa una dilución ${ }^{20}$ y/o menoscabo y/o perjuicio del carácter distintivo de la marca renombrada. En mi opinión, la protección de la marca renombrada, una vez acreditado fehacientemente tal carácter en el Estado, debería proceder automáticamente sin necesidad de que su titular acredite ninguno de los supuestos antes señalados (confusión, asociación, conexión, menoscabo, dilución, perjuicio, etcétera) si las marcas en conflicto son idénticas.

Así, los Estados deben establecer mecanismos para que los titulares de marcas renombradas puedan acreditar que su marca es conocida por la generalidad del público del Estado donde demandan protección.

\section{FUNDAMENTOS PARA LA PROTECGIÓN LEGAL}

DE LAS MARCAS NOTORIAS Y RENOMBRADAS

Por lo general los Estados conceden una tutela a las marcas usuales, pero esta protección quedaría incompleta si no se otorga adicionalmente defensa a las marcas notorias y renombradas. ${ }^{21}$

zación”. Así, marcas líderes como "Teflón”, "Likra" "Bimbo" o “Celofán” pueden ser consideradas genéricas del producto o servicio, lo que pudiera conllevar a su pérdida de capacidad distintiva, y en muchas legislaciones a su cancelación. A efecto de prevenir la "vulgarización" de este tipo de marcas, véase Casulá (2017).

20 En Estados Unidos, en la sentencia de Jada Toys, Inc. vs. Mattel, Inc., 518 F.3d 628, 634 (9th Cir. 2007), se estableció que para reclamar la dilución de una marca, el demandante debía alegar necesariamente que su marca era famosa y distintiva, pues la dilución es propia de este tipo de marcas. Véase Ball y Bittman (2016).

21 Fernández-Nóvoa (2004) afirma que la protección de la marca renombrada frente a su utilización respecto de productos o servicios no similares constituye una pieza indispensable del sistema de marcas. Esta tutela especial, sin embargo, no ha sido fruto de la casualidad, sino del esfuerzo de la doctrina y sobre todo de la jurisprudencia, que han permitido su progresivo reconocimiento. Dentro de este reconocimiento, hay que destacar la labor creadora desarrollada por los tribunales alemanes, que ha hecho posible que la protección de la marca renombrada más allá de la regla de la especialidad sea actualmente uno de los pilares básicos del derecho europeo de marcas. En esta evolución jurisprudencial es importante destacar los siguientes precedentes: en primer lugar, la Sentencia del Reichsgericht, del 12 de enero de 1927 (véase GRUR 1927), que concedió por primera vez a una 
Muchos son los elementos que pueden justificar la protección a las marcas notorias y renombradas, ${ }^{22}$ consistente en dotar a las marcas notoria y renombrada de un régimen de protección reforzada; dentro de los

marca (Salamander) una protección que se extendía más allá de la regla de la especialidad. En segundo lugar, la Sentencia del Reichsgericht de 26 de febrero de 1945 (véase GRUR 1951), en la que el Tribunal Supremo del Reich - apoyándose en normas civiles sobre la protección del nombre - mantuvo que a pesar de no ser similares los productos diferenciados por las marcas enfrentadas, era indudable que la fuerza distintiva de la marca de la demandante resultaba debilitada como consecuencia del uso de la marca por parte de la demandada. En tercer lugar, y en una etapa posterior a la Segunda Guerra Mundial, el Tribunal Supremo alemán (Bundesgerichtshof) en diversas sentencias (Fernández-Nóvoa 2004 y Monteagudo 1995) continuó protegiendo las marcas renombradas más allá de la regla de la especialidad, ramificando su criterio en dos líneas: una que, apoyándose en las normas civiles sobre responsabilidad extracontractual, redoblaba la protección de la marca renombrada (berühmte Marke) frente al riesgo de debilitamiento, y una segunda que, basándose en la cláusula general prohibitiva de la competencia desleal, protegía la marca conocida (bekannte Marke) contra el aprovechamiento de su prestigio por parte de un tercero. Por último, es necesario señalar que el tribunal alemán continuó tutelando la marca renombrada más allá del principio de la especialidad, no sólo por entender que la utilización de la misma por parte de un tercero, para diferenciar productos o servicios diversos, determinaba el debilitamiento de su fuerza distintiva, sino también para evitar actitudes parasitarias de terceros con la intención de aprovechar su prestigio. Véase Concepción (2003)

22 A este respecto, Bercovitz (2002) menciona que la protección de la notoriedad o renombre de un signo se debe establecer en dos puntos fundamentales. En primer lugar, en la eliminación de la necesidad de registrar la marca notoria o renombrada para tener protección jurídica. En segundo lugar, en la supresión de la aplicación de la regla de la especialidad para este tipo de signos, por lo que su protección abarcará productos o servicios más allá de los registrados con la marca notoria o renombrada. Por su parte, Massaguer (2003) mantiene que la protección de las marcas notorias y renombradas, primeramente fue adoptada por la legislación de competencia desleal, pero hoy en día se ha consolidado en el seno del sistema de marcas, tanto entre las prohibiciones de registro como en la fijación del alcance del derecho de marca reconocido a su titular y, en particular, mediante la extensión de unas y otro a casos distintos de los que afectan a productos o servicios similares y entrañan un riesgo de confusión. Asimismo, Rangel (1993) sostiene que la protección a la marca notoria se justifica por tres razones: en primer lugar, en beneficio del dueño de la marca: por su inversión, por la introducción del producto y la apertura, conservación e incremento del mercado, por la calidad de la mercancía, por la fama y prestigio de la marca, y por el valor económico del signo. En segundo lugar, por el beneficio a los consumidores: para evitar ser engañados en cuanto al origen del producto y para evitar ser defraudados por la diferente calidad. Y, en tercer lugar, para evitar el desvío de la clientela a favor del competidor, impedir el enriquecimiento ilegítimo del competidor y prevenir el descrédito que su conducta origina en perjuicio del propietario de la marca notoria. 
que destacan los siguientes: 1) la protección al consumidor de una marca notoria o renombrada; 2) la imagen de calidad del producto o servicio que ostenta una marca notoria o renombrada; 3) el aprovechamiento indebido del renombre o notoriedad de una marca y, por último, 4) la dilución de una marca notoria o renombrada.

\section{La protección al consumidor de una marca notoria o renombrada}

Una de las funciones principales de la marca es diferenciar productos o servicios de su competencia, con objeto de que el público consumidor pueda identificar indubitablemente el producto o servicio que está adquiriendo. Es lamentable la situación en que un consumidor adquiere un producto o servicio pensando que está obteniendo otro, en virtud de que el producto conseguido ostenta una marca igual o parecida en grado de confusión a una marca notoria o renombrada. ${ }^{23}$

Pues bien, las legislaciones de cada Estado deben evitar que el público consumidor caiga en el error de confundir una marca usual con una marca que en el propio Estado ha adquirido notoriedad o renombre. ${ }^{24}$

23 Una marca puede llegar a ser notoria o renombrada sin necesidad de estar en uso en el Estado donde se pretende obtener protección en contra del registro y/o uso por parte de un tercero. En efecto, los medios de comunicación (en especial Internet) han permitido que el conocimiento de un signo trascienda fronteras, independientemente de su uso fuera del país donde se originó el signo. A este respecto, Lefebvre (2005) mantiene que el grado de conocimiento de una marca a lo largo del territorio de un Estado para determinar su notoriedad y renombre pude estar dado entre otros factores por la publicidad realizada a través de prensa escrita, radio y televisión, publicaciones como consecuencia del patrocinio de eventos deportivos, participaciones en congresos, o bien panfletos publicitarios. Por su parte, Otamendi (1999) considera que gracias a la publicidad, las marcas cada día tienen mayor difusión internacional. De esta manera, la transmisión de programas de televisión, noticieros y eventos deportivos, así como la circulación de gran cantidad de revistas y diarios extranjeros, permiten el conocimiento de marcas cuyos productos no son vendidos en el país que recibe la publicidad.

24 La protección tutelada a las marcas notorias debe romper con el principio de territorialidad, pero no con el de especialidad. En cambio, la tutela a las marcas renombradas no debe estar limitada ni por el principio de territorialidad ni por el de especialidad.

Esta obra está bajo una Licencia Creative Commons

Atribución-NoComercial-SinDerivar 4.0 Internacional, IIJ-UNAM.

Boletín Mexicano de Derecho Comparado, núm. 157, enero-abril de 2020, pp. 193-220. 


\section{La imagen de calidad del producto o servicio que ostenta una marca notoria o famosa}

Otra función primordial en una marca es atesorar un prestigio en favor de su legítimo creador. En efecto, la marca no sólo permite que el consumidor distinga un producto o servicio de su competencia, sino que adicionalmente, si el producto o servicio al cual se aplica posee buena calidad, permitirá a la marca ir acumulando un prestigio, primeramente ante el público consumidor y posteriormente ante el público en general de un Estado. ${ }^{25}$ Este prestigio, además, puede trascender fronteras y llegar a ser conocido incluso en lugares donde la marca no es usada. ${ }^{26}$

Así las cosas, la buena reputación que obtienen las marcas notorias y renombradas transmiten al público consumidor una información sobre la calidad del producto o servicio ofertado. ${ }^{27}$ Esta información es fruto normalmente de diversos factores, entre los que destacan: 1) inversión; 2) promoción; 3) publicidad, y 4) uso del signo. ${ }^{28}$

25 Las características de las marcas renombradas o famosas es que llegan a ser conocidas por la generalidad del público, independientemente de que tal público sea consumidor de la marca. Por ejemplo, aunque la mayoría del público no sea consumidor de la marca "Ferrari" en automóviles, llega a conocer la fama y prestigio de la misma. En contra de esta opinión se manifiesta Nava (2012). En efecto, este autor señala que necesariamente el conocimiento de la marca debe ser en el público consumidor, y no en el público en general.

26 Normalmente, este conocimiento se logra a través de medios globales de comunicación, como son Internet, radio, televisión o publicidad en publicaciones de circulación mundial.

27 Como bien indica Vargas (2006), la calidad o reputación no es un factor que distinga entre una marca notoria y una renombrada.

28 Como acertadamente opina Monteagudo (1995), la notoriedad o renombre de una marca hoy en día no se debe exclusivamente al uso de la misma. En efecto, los masivos desembolsos publicitarios y las cuidadas estrategias de marketing de los titulares de marcas notorias y renombradas han suplantado los laboriosos años de dedicación para posicionar un signo en el público. En el mismo sentido Ruiz (2009) mantiene que la protección especial a la marca renombrada es un premio "extra" que debe ser otorgado a su titular, por el buen uso de la publicidad y por su propia calidad, sujeto siempre a que el propio propietario del signo acredite ante la autoridad respectiva los requisitos legales para que dicha marca sea considerada bajo esa categoría. 
Por tal razón, es indudable que debe existir una protección especial para este tipo de signos, en contra del aprovechamiento indebido de la imagen de calidad por parte de terceros. ${ }^{29}$

\section{La dilución de una marca notoria o renombrada}

La dilución es un problema que normalmente padecen las marcas que tienen un prestigio o calidad ganada ante el público consumidor. En efecto, las marcas con buena reputación en el mercado son apetecibles a terceros ajenos que desean aprovecharse indebidamente del reconocimiento que la marca tiene en el mercado, lo que conlleva necesariamente a una pérdida o disminución del carácter distintivo del signo en favor de su legítimo creador. ${ }^{30}$

Las marcas notorias y renombradas, al ser consideradas "marcas fuertes", ${ }^{31}$ se encuentran dotadas de un elevado carácter distintivo. En efecto, es indudable que a medida que aumenta el grado de reconocimiento de una marca por parte del público consumidor, se incrementará correlativamente la aptitud de la marca para diferenciar en el mercado los correspondientes productos o servicios (Fernández-Nóvoa 2004)

El carácter distintivo de una marca renombrada se ve fortalecido si existe unicidad en el signo; esto es, si en los restantes sectores del mercado - a los que no dirige su oferta primordialmente - no existen marcas idénticas (Fernández-Nóvoa 2004). En el caso de la marca notoria, la unicidad del signo se puede configurar como la no existencia de marcas idénticas

29 Sobre este tema, Massaguer (2003) mantiene que el titular de una marca renombrada tiene el derecho de apropiarse de las oportunidades de negocio que le brinda la implantación y reputación de su marca en el tráfico económico, fruto del propio esfuerzo, en virtud de que el desarrollo de una marca renombrada exige una decidida política de promoción y calidad, y es resultado de una exitosa estrategia empresarial basada en la creatividad e innovación que requiere la realización de importantes inversiones.

30 En este sentido, Delvasto (2015) mantiene que las marcas famosas o populares en el mercado son atractivas para que terceros busquen obtener un beneficio propio (problema polizón o también llamado free rider). Este uso por parte del tercero ocasiona un detrimento en la imagen de la marca original, que independientemente de que el público consumidor se confunda o no, necesariamente le causa una dilución en su distintividad.

31 De acuerdo con Fernández-Nóvoa (2004), la fortaleza de una marca puede tener su origen en dos causas: la estructura intrínseca del signo, o bien la amplia difusión de la marca entre el público como consecuencia de un uso intensivo de la misma.

Esta obra está bajo una Licencia Creative Commons

Atribución-NoComercial-SinDerivar 4.0 Internacional, IIJ-UNAM.

Boletín Mexicano de Derecho Comparado, núm. 157, enero-abril de 2020, pp. 193-220. 
para productos o servicios similares, aunque pertenezcan a diversas clases del clasificador oficial. En el caso de la marca renombrada o famosa, la unicidad se obtiene con la no existencia de marcas idénticas para cualquier clase de productos o servicios.

En este sentido, el aprovechamiento indebido del carácter distintivo de una marca notoria o renombrada por parte de un tercero ajeno es un fenómeno íntimamente vinculado con el aprovechamiento indebido de la notoriedad o, en su caso, renombre. ${ }^{32}$

Dicho con otras palabras, si el público consumidor comprueba que la marca renombrada es usada por un tercero con relación a productos diferentes de aquellos a los que viene aplicándose tal marca, se origina necesariamente una asociación en su mente, pues el público recordará a la marca renombrada, y — si no logra confundirse - percibirá que la misma no es usada únicamente por el titular originario, lo que afectará necesariamente el carácter distintivo y el potencial publicitario de la marca renombrada (Fernández-Nóvoa 2004). ${ }^{33}$

Por otro lado, y en relación con la marca notoria, también es viable pensar que perderá distintividad el signo si el público consumidor del sector al cual se dirige primordialmente encuentra en el mercado marcas idénticas para productos o servicios similares, que no tienen el mismo origen empresarial.

Así las cosas, el hecho de permitir el uso en el tráfico económico de marcas idénticas a la renombrada, a través de diversos empresarios - aunque sea en productos o servicios diferentes a los que la marca renombrada dirige primordialmente su oferta-, afectará sin duda a la unicidad de la

32 La afirmación la hace Fernández-Nóvoa (2004) refiriéndose exclusivamente a las marcas renombradas.

33 En este sentido, Monteagudo (1995) opina que la necesidad de proteger a la marca renombrada se justifica - entre otras razones - por la dilución del valor atractivo del signo, por la forma en que es usada por terceros $v$. gr: cuando pierde buena parte de su dimensión distintiva y se aproxime al carácter banal, fruto de su proliferación como distintivo para múltiples clases de productos o servicios. El propio autor (1995) agrega que en el caso de que la marca renombrada sea utilizada por un tercero en conexión con productos o servicios de naturaleza incompatible o de mala calidad, la marca resultará erosionada y perderá credibilidad, afectando notablemente a su propio valor atractivo respecto a la oferta originaria. 
marca renombrada, a su imagen positiva (prestigio o goodwill), ${ }^{34}$ así como a su carácter distintivo, que necesariamente sufrirá un menoscabo. ${ }^{35}$

En este mismo sentido, y con relación a la marca notoria, también se puede decir que el uso de marcas idénticas por parte de terceros, en productos o servicios similares, afectará igualmente su distintividad y afectará su unicidad, prestigio y carácter distintivo. Consecuentemente, se verá afectada también la imagen positiva que había ganado dentro del sector del público al cual se dirige.

Por las razones antes expuestas, y a efecto de evitar un menoscabo en la distintividad de las marcas renombradas y notorias, que afecte la imagen positiva que han implantado en el público consumidor, es importante otorgarles una tutela especial que proteja el esfuerzo e inversión de sus titulares. ${ }^{36}$

\section{CONCEPTO DE MARGA NOTORIA EN LA COMUNIDAD ANDINA DE NAGIONES Y AUSENGIA DE LA FIGURA DE LA MARGA RENOMBRADA O FAMOSA}

El artículo 224 de la Decisión 486 relativa al régimen común de propiedad industrial (D 486) en la Comunidad Andina de Naciones (CAN) ${ }^{37}$ hace referencia a la marca notoria como "notoriamente conocida", e indica que es aquella que es reconocida como tal en cualquier país miembro dentro del

34 Fernández-Nóvoa (1978) afirma que es innegable que el ordenamiento jurídico debe reconocer y proteger adecuadamente las marcas de productos o servicios en su función condensadora de goodwill.

35 En este punto, Fernández-Nóvoa (2004) considera que al invocar el menoscabo en el renombre de la marca, el titular de la misma deberá probar, en primer término, que su marca posee una imagen positiva en el tráfico comercial, además de que el uso de un signo idéntico o semejante por parte de un tercero provocaría un menoscabo o perjuicio de la imagen positiva de la marca renombrada. El propio autor (1984) opina que un factor básico del debilitamiento de la marca renombrada lo conforma el supuesto de que un tercero emplee una marca idéntica o muy semejante a la marca renombrada para designar productos de bajo precio o de calidad inferior.

36 Monteagudo (1995) mantiene que es inobjetable exigir una protección extraordinaria para la marca implantada en la generalidad del público consumidor, frente al riesgo de dilución o aguamiento.

37 Decisión 486. Régimen Común sobre Propiedad Industrial (s. d.), "La Comisión de la Comunidad Andina", disponible en: http://wwwewipo.int/edocs/lexdocs/laws/es/can/ can012es.pdf(consultado el 20 de enero de 2018). 
sector pertinente, ${ }^{38}$ independientemente del modo en que el signo hubiera sido conocido.

Asimismo, el artículo 229 D 486 prescribe con acierto que para determinar la calidad de una marca notoriamente conocida no es necesario el uso o registro de la marca en algún Estado miembro de la CAN.

De lo anterior se colige:

a) que basta que algún Estado miembro de la CAN declare a una marca como notoriamente conocida para que tal declaratoria surta efectos en todos los países miembros;

b) que la marca notoriamente conocida no debe ser conocida por la generalidad del público, sino exclusivamente por el sector del público pertinente (al cual dirige de manera principal su oferta), y

c) que no es necesario el uso o registro de la marca notoriamente conocida para determinar su notoriedad sino que basta que se acredite el conocimiento del signo en el sector pertinente. ${ }^{39}$

Por otro lado, considero un error que el artículo 228 a) D486 señale que uno de los factores para acreditar la notoriedad de la marca es el grado de conocimiento entre los miembros del sector, siendo que el grado de conocimiento en el sector es el objetivo principal a demostrar a efecto de acreditar la notoriedad del signo; es decir, el grado de conocimiento en el sector no es un factor más de prueba, sino que constituye la finalidad que se debe buscar con los demás elementos de prueba enunciado en dicho artículo (Magaña Rufino 2010, 83). ${ }^{40}$

38 El artículo 230 D486 define al sector pertinente como: “a) los consumidores reales o potenciales del tipo de productos o servicios a los que se aplique la marca; b) las personas que participan en los canales de distribución o comercialización del tipo de productos o servicios a los que se aplique el signo; y, c) los círculos empresariales que actúan en giros relativos al tipo de establecimiento, actividad, productos o servicios a los que se aplique la marca".

39 La marca pudo haber sido conocida en el sector por publicidad a través de televisión, radio, revistas, Internet, actores o deportistas que usan el signo, competiciones a nivel mundial, etcétera.

40 No obstante, autores como Fernández-Nóvoa (2004) mantienen que el grado de reconocimiento de la marca notoria en el público es un elemento más a considerar. En efecto, tal autor argumenta que adicionalmente a este reconocimiento se debe considerar la duración, magnitud, promoción, alcance geográfico del uso de la marca, así como el valor asociado a la marca y reconocimiento como tal por parte de la autoridad. 
Por último, la D 486 CAN no define ni regula a la figura de la marca renombrada o famosa, ${ }^{41} \mathrm{y}$ sólo concede una tutela especial a la marca notoria a efecto de protegerla contra el uso o registro indebido en cualquier clase de productos o servicios (artículos 136 h), 155 e) y f) y 226 D486).

Así, se puede afirmar que en el régimen comunitario andino el renombre o fama se protege a de manera "adoptiva" a través de la figura de la marca notoria (Haro 2019).

\section{PROTEGCIÓN CONTRA EL REGISTRO DE MARCAS NOTORIAS O RENOMBRADAS EN LA COMUNIDAD ANDINA DE NAGIONES}

Los artículos 136 h), 225, 227 y 235 de la D 486 CAN tutelan protección a la marca considerada notoriamente conocida (notoria) en la CAN en contra del registro indebido por parte de un tercero ajeno al signo. La protección implica la reproducción, imitación, traducción, transliteración o transcripción total o parcial del signo.

Por su parte, el artículo 233 D 486 CAN protege al titular de una marca notoriamente conocida (notoria) en la CAN, cuando hubiera sido inscrito indebidamente en cualquier Estado miembro de dicha Comunidad como parte de un nombre de dominio o una dirección de correo electrónico por un tercero no autorizado. ${ }^{42}$

Cabe señalar que en virtud de que no existe la figura de la marca renombrada o famosa en la CAN, este ordenamiento no prevé una tutela

41 No obstante, hay autores (Vargas Mendoza (2006) que opinan que no hay necesidad de distinguir entre marca notoria y renombrada en la Comunidad Andina, puesto que la D 486 CAN protege a cualquier signo notorio contra su dilución y uso parasitario. A este respecto, es necesario señalar que si no se hace la distinción entre estas figuras en la CAN, al menos se debe regular de manera diferente cuando la marca notoria llega a ser conocida por la generalidad del público (mayor protección) que cuando la marca sólo es conocida por el sector al cual dirige su oferta (menor tutela).

42 El propio artículo 233 D 486 CAN indica que a petición expresa del titular de la marca notoriamente conocida (notoria) la autoridad nacional competente ordenará la cancelación o la modificación de la inscripción del nombre de dominio o dirección de correo electrónico, siempre que el uso de ese nombre o dirección fuera susceptible de tener alguno de los efectos mencionados en el primer y segundo párrafos del artículo 226 D 486 CAN.

Esta obra está bajo una Licencia Creative Commons

Atribución-NoComercial-SinDerivar 4.0 Internacional, IIJ-UNAM.

Boletín Mexicano de Derecho Comparado, núm. 157, enero-abril de 2020, pp. 193-220. 
expresa de protección contra el registro indebido por parte de un tercero ajeno.

No obstante, la D 486 CAN concede una protección ampliada a la marca notoriamente conocida (notoria) - a efecto de evitar el registro por parte de un tercero - que aplica de modo general a todos los productos o servicios siempre y cuando exista un riesgo de confusión o de asociación con el legítimo creador o comercializador del signo notorio, o exista un aprovechamiento injusto del prestigio del signo notorio, o bien una dilución de su fuerza distintiva o de su valor comercial o publicitario (artículos 136 h) y 227 D 486 CAN).

Acorde con lo anterior, podemos obtener las siguientes conclusiones:

1. La D 486 CAN sólo prevé una tutela general en contra del registro indebido de una marca notoriamente conocida (notoria) por parte de un tercero. Esta protección no distingue si ese tercero pretende registrar la marca notoriamente conocida (notoria) en los mismos o similares productos o servicios o en productos o servicios diferentes a los que se aplica primordialmente la marca notoriamente conocida (notoria).

2. La protección que la D 486 CAN concede a la marca notoriamente conocida (notoria) en contra del registro indebido por parte de un tercero exige que su legítimo creador acredite que el tercero - con la concesión del registro - causará confusión o asociación con los productos, servicios, o bien con el titular de la marca notoriamente conocida (notoria), o que obtendrá un aprovechamiento injusto del prestigio del signo notorio, o bien le causará una dilución de su fuerza distintiva o un perjuicio en su valor comercial publicitario.

3. La D 486 CAN no prevé una tutela que aplique en forma directa para proteger al titular de una marca notoriamente conocida (notoria) en contra del registro de una marca idéntica por parte de un tercero en productos o servicios iguales o similares.

4. En virtud de que en la D 486 CAN no existe la figura de la marca renombrada o famosa, se concede a la marca notoriamente conocida una protección excesiva - propia de la marca renombrada o famosa - en el registro de la marca por parte de un tercero en cualquier producto o servicio cuando se acrediten diversas conductas (riesgo de confusión o asociación, o aprovechamiento injusto 
del prestigio del signo notorio, o dilución ${ }^{43}$ de su fuerza distintiva o de su valor comercial o publicitario).

5. La obligación que impone la D 486 CAN al legítimo titular de una marca notoriamente conocida (notoria) en el sentido de acreditar en todos los casos conductas de aprovechamiento injusto del prestigio del signo notorio, y/o dilución de su fuerza distintiva y/o pérdida de su valor comercial publicitario, para conceder protección en contra del registro de la marca notoriamente conocida (notoria) por parte de un tercero, sólo conlleva a que se abran muchos litigios, y a que en cada uno se presenten las mismas pruebas, situación que puede ser evitada si la D 486 CAN estableciera procedimientos para que los titulares de marcas notoriamente conocidas (notorias) de cualquier parte del mundo pudieran acreditar el carácter notorio de su marca en la CAN, y una vez probado tal carácter se concediera una protección directa (sin necesidad de demostrar conductas de confusión, aprovechamiento injusto de la marca, dilución o pérdida de su valor comercial) en contra del registro de la misma marca notoria por parte de un tercero en productos o servicios iguales o similares.

6. Por último, cabe señalar que el artículo 235 D 486 CAN concede la posibilidad a las oficinas locales de los Estados miembros del CAN, de cancelar un registro de marca considerado notoriamente conocido en dicho Estado al momento en que fue solicitado por un tercero ajeno, siempre y cuando la propia legislación del país lo prevea, y el registro sea idéntico o similar al considerado notorio.

43 La falta de la figura de la marca renombrada o famosa en la CAN acarrea errores de confusión como en el caso de la Resolución núm. 2531-2008/TPI-INDECOPI del 16 de octubre de 2008, emitida por el Indecopi (Instituto Nacional de Defensa de la Competencia y de la Protección de la Propiedad Intelectual) del Perú con relación a la figura de la dilución — propia de las marcas renombradas o famosas - : "si bien — de acuerdo a la doctrina antes citada - la figura jurídica de la dilución sólo se aplica a marcas renombradas, ésta también debe ser analizada cuando se haya reconocido que una marca goza de la condición de notoria, dado que en la actual norma andina — entiéndase la Decisión 486 no se hace distinción entre marcas notorias y renombradas". Véase Rodríguez (2010).

Esta obra está bajo una Licencia Creative Commons

Atribución-NoComercial-SinDerivar 4.0 Internacional, IIJ-UNAM.

Boletín Mexicano de Derecho Comparado, núm. 157, enero-abril de 2020, pp. 193-220. 


\section{PROTEGGión GONTRA EL USO DE UNA MARGA NOTORIA O RENOMBRADA EN LA GOMUNIDAD ANDINA DE NACIONES}

Los artículos 155 e) y f), 225, 226, 227, 231, 232 y 234 de la D 486 CAN tutelan protección a la marca considerada notoriamente conocida (notoria) en la CAN en contra del uso indebido por parte de un tercero ajeno al signo.

La protección antes señalada - a diferencia de la protección en contra del registro, cuya tutela es única- se divide en dos vertientes.

a) protección en contra del uso por parte de un tercero en productos o servicios iguales o similares a los aplicados por la marca notoriamente conocida, $y$

b) protección en contra del uso por parte de un tercero en productos o servicios diferentes a los que dirige de manera primordial su oferta la marca notoriamente conocida.

\section{Protección en contra del uso por parte de un tercero en productos o servicios iguales o similares a los aplicados por la marca notoriamente conocida}

De conformidad con el artículo 226 D 486 CAN, para la procedencia de esta tutela, el titular de la marca notoriamente conocida (notoria) requiere acreditar que el uso de la marca por parte del tercero causa confusión con relación al establecimiento, la actividad comercial o industrial, o bien los productos o servicios en el público consumidor.

Cabe señalar que el uso por parte del tercero implica la utilización igual o similar del signo notorio, en su totalidad o en una parte esencial, así como la reproducción, imitación, traducción, transliteración o transcripción total o parcial del mismo.

Con relación a la protección que dispensa la D 486 CAN en contra del uso ilegítimo de una marca notoriamente conocida (notoria) por parte de un tercero en productos o servicios iguales o similares a los que aplica el signo notorio, podemos obtener las siguientes conclusiones:

a) a) La D 486 CAN no prevé una tutela que aplique en forma automática para proteger al titular de una marca notoriamente conoci- 
da (notoria) en contra del uso idéntico de su marca por parte de un tercero en productos o servicios iguales o similares.

b) b) La D 486 CAN prevé una tutela adecuada para proteger al titular de una marca notoriamente conocida (notoria) en contra del uso de un signo similar por parte de un tercero en productos o servicios iguales o similares. En efecto, en este caso el artículo 226 D 486 CAN exige de manera correcta que el afectado demuestre supuestos de confusión entre los signos en conflicto, lo cual considero es loable.

\section{Protección en contra del uso por parte de un tercero en productos o servicios diferentes a los aplicados por la marca notoriamente conocida}

Acorde con los artículos 155 e) y f), y 226 D 486 CAN, para la tutela de este supuesto, el titular de la marca notoriamente conocida (notoria) requiere acreditar alguno de las siguientes causales: a) que exista un riesgo de confusión o de asociación con el titular del signo, o con sus establecimientos, actividades, productos o servicios; b) que el uso del signo realizado por parte del tercero le causa un daño económico o comercial injusto al titular del signo notorio por razón de una dilución de la fuerza distintiva o del valor comercial o publicitario del signo, o bien, c) que existe un aprovechamiento injusto - por parte del tercero usuario - del prestigio o del renombre del signo.

El uso por parte del tercero - antes referido - implica la utilización igual o similar del signo notorio, en su totalidad o en una parte esencial, así como la reproducción, imitación, traducción, transliteración o transcripción total o parcial del mismo.

Cabe señalar que la protección otorgada en el artículo 155 e) y f) D 486 CAN, en mi opinión es innecesaria ante la tutela que concede el artículo 226 D 486. En efecto, la protección dictada por el artículo 155 e) y f) CAN requiere forzosamente del registro de la marca notoriamente conocida (notoria) en cualquier Estado miembro CAN, pero el artículo 226 D 486 CAN no precisa de un registro para conceder una protección 
ampliada; ${ }^{44}$ incluso el propio artículo 229 D 486 CAN señala claramente que no se negará la calidad de notorio a un signo - y por ende no se negará la protección contenida en el título XIII D 486 CAN - aun cuando no se encuentre registrado en algún país miembro de la CAN.

Con relación a la protección que dispensa la D 486 CAN en contra del uso ilegítimo de una marca notoriamente conocida (notoria) por parte de un tercero en productos o servicios diferentes a los que se dirige primordialmente la marca notoriamente conocida (notoria), podemos obtener las siguientes conclusiones:

1. En virtud de que en la D 486 CAN no existe la figura de la marca renombrada o famosa, se concede a la marca notoriamente conocida una protección excesiva - propia de la marca renombrada o famosa - en el uso de la marca por parte de un tercero en cualquier producto o servicio, cuando se acrediten alguna de las siguientes conductas: a) riesgo de confusión o de asociación con el titular del signo, con sus establecimientos, actividades, productos o servicios; b) un daño económico o comercial injusto al titular del signo por razón de una dilución de la fuerza distintiva o del valor comercial o publicitario del signo, o bien, c) que exista un aprovechamiento injusto del prestigio o del renombre del signo por parte del tercero (artículo 226 D 486 CAN).

2. La D 486 CAN no prevé una tutela que aplique en forma específica para proteger al titular de una marca notoriamente conocida (notoria) en contra del uso idéntico de su marca por parte de un tercero en productos o servicios diferentes a los que aplica la marca notoria.

3. Sólo en el caso de que las marcas en conflicto no sean idénticas, y un tercero ajeno pretendiera usarla en productos o servicios diferentes a los que se dirige en modo primordial la marca notoriamente conocida (notoria), el titular de la marca notoriamente conocida (notoria) debería acreditar: a) el conocimiento de su marca por la

44 La protección que concede el artículo 155 e) y f) D 486 CAN aplica cuando el tercero usa un signo idéntico o similar a la marca notoriamente conocida (notoria); mientras que la tutela del artículo 226 D 486 CAN concede, además de la utilización del signo igual o similar a la marca notoria, otras conductas, como son la reproducción, imitación, traducción, transliteración o transcripción total o parcial del signo notoriamente conocido. 
generalidad del público en cualquier Estado miembro de la CAN, y b) exclusivamente supuestos de similitud o parecido en grado de confusión para el público.

En mi opinión, en ningún caso el titular de la marca notoriamente conocida (notoria) debería acreditar causales relativas a daño económico o comercial injusto al titular del signo por razón de una dilución de la fuerza distintiva o del valor comercial o publicitario del signo, o la existencia de un aprovechamiento injusto del prestigio o del renombre del signo por parte del tercero para la procedencia de la tutela legal.

\section{Propuesta de Reformas a la D 486 GAN}

1. Incluir en la D 486 un procedimiento de declaratoria de marca notoria, a efecto de que los interesados puedan presentar toda clase de pruebas para acreditar el conocimiento de su marca en el sector al cual dirigen primordialmente su oferta, con objeto de obtener tal declaratoria por parte de la CAN que les conceda certeza jurídica de la notoriedad de su marca ante cualquier Estado miembro. La declaratoria deberá ser temporal (se sugiere cinco años) y sujeta a renovación si el titular acredita que siguen vigentes las condiciones que la propiciaron, es decir, que la marca es conocida por el sector o la generalidad del público.

2. Una vez concedida la declaratoria de notoriedad de la marca por parte de un Estado miembro de la CAN, otorgar protección al signo en contra del uso o registro de la misma marca por parte de un tercero, en productos o servicios iguales o similares de forma directa (sin necesidad de que el titular de la marca notoriamente conocida deba presentar ninguna clase de pruebas).

En caso de que el uso o registro por parte del tercero sea de una marca no idéntica, pero similar, entonces el titular de la marca notoriamente conocida (notoria) deberá acreditar de forma exclusiva supuestos de similitud o parecido en grado de confusión para el público - entre las marcas en conflicto- a efecto de obtener protección. 
3. Incluir la figura de la marca renombrada o famosa - y su procedimiento de Declaratoria - a efecto de protegerla en contra del uso o registro por parte de terceros en cualquier producto o servicio. Una vez concedida la declaratoria de renombre o fama de la marca por parte de un Estado miembro de la CAN, se deberá otorgar protección al signo en contra del uso o registro de la misma marca por parte de un tercero, en cualquier producto o servicio de forma automática (sin necesidad de que el titular de la marca notoriamente conocida deba presentar ninguna clase de pruebas) si los signos en conflicto son idénticos.

Es decir, si las marcas en conflicto son idénticas, en ningún caso el titular de la declaratoria de marca renombrada o famosa debería acreditar causales relativas a daño económico o comercial injusto al titular del signo por razón de una dilución de la fuerza distintiva o del valor comercial o publicitario del signo, o la existencia de un aprovechamiento injusto del prestigio o del renombre del signo por parte del tercero para la procedencia de la tutela legal.

En caso de que el uso o registro por parte del tercero sea de una marca no idéntica, pero similar, entonces el titular de la declaratoria de marca renombrada o famosa deberá exclusivamente acreditar supuestos de similitud o parecido en grado de confusión para el público - entre las marcas en conflicto - a efecto de obtener protección.

4. En caso de no incluir la figura de la marca renombrada o famosa en la D 486, se deberá permitir que los titulares de marcas notoriamente conocidas (notorias) puedan acreditar el conocimiento generalizado de su marca en algún Estado de la CAN, y una vez acreditado lo anterior, se debe conceder protección de forma directa (sin necesidad de comprobar ningún supuesto relativo a daño económico o comercial injusto al titular del signo por razón de una dilución de la fuerza distintiva o del valor comercial o publicitario del signo, o la existencia de un aprovechamiento injusto del prestigio o del renombre del signo por parte del tercero) en contra del uso o registro de un tercero de la misma marca.

Si el uso o registro por parte de un tercero es de una marca similar a la marca notoria que ha acreditado conocimiento generalizado del público en cualquier Estado miembro de la CAN, entonces se debe 
requerir que el titular de la marca notoria acredite exclusivamente supuestos de parecido en grado de confusión para el público de las marcas en conflicto, a efecto de conceder protección en contra del uso o registro en cualquier producto o servicio.

En este caso no se debe obligar al titular de la marca notoria a acreditar causales relativas a daño económico o comercial injusto al titular del signo por razón de una dilución de la fuerza distintiva o del valor comercial o publicitario del signo, o la existencia de un aprovechamiento injusto del prestigio o del renombre del signo por parte del tercero para conceder tutela en contra del uso o registro por parte de un tercero de una marca similar a la notoria.

5. Cambiar los supuestos contenidos en los artículos 136 h), 155 e) y f) y 226, D 486 (pues son difíciles de acreditar en la práctica) por "el conocimiento de la generalidad del público en un Estado miembro de la CAN"; así, el legítimo creador de la marca notoriamente conocida (notoria) sólo tendría que acreditar ante la oficina de marcas de cualquier Estado miembro de la CAN, que su signo es conocido por la generalidad del público para que procediera la tutela automática en toda clase de productos o servicios en cualquier país miembro de la CAN.

\section{BIBLIOGRAFÍA}

ARCALÁ, Marcos, 1999. "Notoriedad y renombre de las marcas nacionales en la primera Directiva sobre marcas a la luz de la jurisprudencia reciente del Tribunal de Justicia de la Unión Europea", disponible en: https://libros-revistas-derecho.vlex.es/vid/notoriedad-renombre-nacionales-reciente-262868.

Ball, E. Y Bittman, C. 2016. "Almost Famous: Trademark Owners May Find Dilution Claims Out of Reach", disponible en: http://law-articles. vlex.com/vid/almost-famous-trademark-owners-655981509.

Bercovitz Rodríguez Cano, A. 2000. Apuntes de derecho mercantil, Navarra, Aranzadi.

Bercovitz Rodríguez CANO, A. 2002. Introducción a las marcas y otros signos distintivos en el tráfico económico, Navarra, Aranzadi. 
Botana Agra, M. 2002. Lecciones de derecho mercantil, España, Universidad de Santiago de Compostela.

Gasado Cerviño, A. 2000. Derecho de marcas y protección de los consumidores, el tratamiento del error en el consumidor, Madrid, Tecnos.

CÁsulA, J. 2017. "Protección de marcas notorias ante el riesgo de vulgarización", Actualidad Furídica Aranzadi, núm. 933.

CONCEPCiÓn Rodríguez, J. L. 2003. "La protección de la marca renombrada", Cuadernos de Derecho Fudicial, núm. 9.

Delvasto Perdomo, G. A. 2015. "¿Puede una marca notoriamente conocida o famosa existente en un país extranjero, tener validez en Estados Unidos", Revista de Derecho, Barranquilla, núm. 43.

FERnÁNDEZ-NóvOA G. 1978. "Las funciones de la marca", $A D I$, t. V, Santiago de Compostela.

Fernández-NóvoA C. 1984. Fundamentos de derecho de marcas, Madrid, Montecorvo.

Fernández-Nóvoa C. 2004. Tratado sobre derecho de marcas, Madrid, Marcial Pons.

Garza Barbosa, R. 2010. "Steele vs. Bulova Watch Co., de la aplicación extraterritorial del Lanham Act estadounidense en México y de la marca notoriamente conocida", Boletín Mexicano de Derecho Comparado, 129(43).

Gondra Romero, J. M. 1996 "Teoría general de signos de empresa", en IgLesias PRADA, Juan Luis (coord.), Estudios jurídicos en homenaje al profesor Aurelio Menéndez, vol. 1.

GonzÁLEz Bueno, C. 2005. Marcas notorias y renombradas en la ley y la jurisprudencia, Madrid, La Ley.

HARO BRAVO, Z. V. 2019. "Las marcas notorias y renombradas, conceptualización, protección y publicidad", Quito, Ecuador, Universidad Internacional de la Rioja, disponible en: https://reunir.unir.net/bitstream/ handle/123456789/8253/HARO\%20BRAVO\%2c\%20ZAIRA\%20VANESSA.pdf? sequence $=1$ छis Allowed $=y$.

Jalife Daher, M. 2014. Derecho mexicano de la propiedad industrial, México, Tirant lo Blanch.

Koplow, M. Y Nelson, G. J. 2019. "Lady Gaga: Famous Performer; not so Famous Trademark", disponible en: http://law-articles.vlex.com/vid/ lady-gaga-famous-performer-692624497. 
KoRS, J. A. 1999. "La marca, una herramienta del derecho de la competencia", Temas de Derecho Industrial y de la Competencia, núm. 3.

Lefebvre, F. 2005. Marcas y nombres de domini, Santiago de Compostela, Francis Lefebvre.

Magaña RufinO, J. M. 2010. Las marcas notoria y renombrada en el derecho internacional y mexicano, México, Porrúa.

Magaña Rufino, J. M. 2014. Derecho de la propiedad industrial en México, México, Porrúa.

MASSAgUer FUentes, J. 2003. La protección jurídica de la marca no inscrita en derecho de marcas, Barcelona, Bosch.

Monteagudo Monedero, M. 1995. La protección de la marca renombrada, Madrid, Civitas.

Nava Negrete, J. 2012. Tratado sobre derecho de marcas, México, Porrúa.

Otamendi, J. 1999. Derecho de marcas, Buenos Aires, Abeledo-Perrot.

Otero Lastres, J. M. 1997. Memorias del seminario internacional "La integración, derecho y los tribunales comunitarios", Quito, Noplu.

PACÓn, A. M. 1993. "Marcas notorias, marcas renombradas, marcas de alta reputación", Revista de la Facultad de Derecho PUCP, núm. 47.

Rangel Medina, D. 1993. "La protección de la marca notoria en la jurisprudencia mexicana", Actas de Derecho Industrial y Derechos de Autor, t. 10.

RODRÍGUEz GARCíA, G. M. 2010. "Las marcas notoriamente conocidas en el nuevo precedente del Indecopi. El complejo camino de la legalidad", Diálogo con la furisprudencia, t. 137.

Ruiz MEDRANO S. F. 2009. "La marca renombrada, un obstáculo a la libre competencia", Revista Boliviana de Derecho, enero, núm. 7.

SANZ DE ACEDO, E. 2000. "La protección de la marca renombrada en el derecho comunitario", $R D M, 236$.

VARGas Mendoza, M. 2006. "La marca renombrada en el actual régimen comunitario andino de propiedad intelectual", Foro Revista de Derecho, UASB-Ecuador, núm. 6.

WANG, J. 2012. "Comment and Analysis on Well-Known Trademarks in The Internet Industry", disponible en: http://cn.vlex.com/vid/commentanalysis-trademarks-internet-523656946. 